\title{
Cardiac metastatic melanoma
}

\author{
Jay Ramchand, ${ }^{1}$ Geoffrey R Wong, ${ }^{2}$ Matias B Yudi, ${ }^{1}$ Stephen Sylivris ${ }^{1}$
}

${ }^{1}$ Department of Cardiology, Austin Hospital, Melbourne, Victoria, Australia

${ }^{2}$ Department of Cardiology, Royal Melbourne Hospital, Melbourne, Victoria, Australia

\section{Correspondence to} Dr Geoffrey R Wong, geoffrey.wong@adelaide.edu. $\mathrm{au}$

Accepted 1 May 2016
CrossMark

To cite: Ramchand J, Wong GR, Yudi MB, et al. BMJ Case Rep Published online: [please include Day Month Year] doi:10.1136/ bcr-2016-215881

\section{DESCRIPTION}

We describe the case of a 55 -year-old woman presenting with a recent onset of mild cough and no other specific cardiovascular symptoms, and with a normal examination. Salient past medical history included BRAF-positive melanoma resected from the small bowel with abdominal, left inguinal and pulmonary metastases, 2 years prior. Following immunotherapy with combined dabrafenib and trametinib for 6 months and subsequently, ipilimumab, complete remission was achieved. The only other significant history was of type 2 diabetes mellitus with metformin therapy.

Plain radiographs of the chest were unremarkable, and a subsequent fluorodeoxyglucose positron emission tomography (FDG PET) demonstrated focal uptake in the anterior left ventricle (figure 1). Transoesophageal echocardiography (TOE) demonstrated a large, voluminous intracavitary left ventricular mass $(45 \times 25 \mathrm{~mm})$ attached to the mid anterior wall without evidence of obstruction (figure 2, video 1). Cardiac MRI confirmed a mass with increased signal intensity on T1-weighted imaging suggestive of metastatic melanoma in the left ventricle (figure 3). Importantly, there was no evidence of myocardial infiltration after gadolinium administration (figure 4). Given the absence of other distant metastasis, surgery was recommended; she underwent an uncomplicated

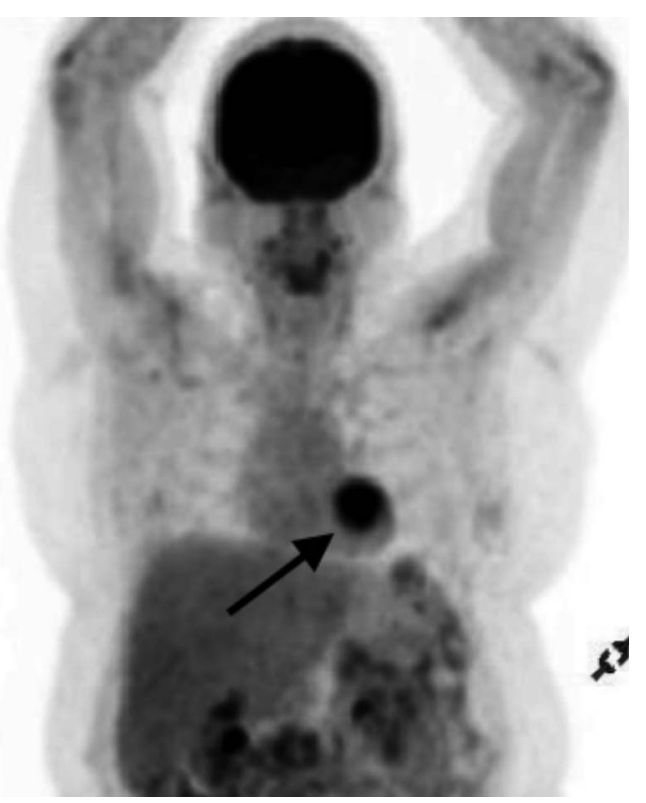

Figure 1 Fluorodeoxyglucose (FDG) positron emission tomography. A focal area of FDG uptake which in the high anterior wall of the left ventricle is not typical of normal ventricular wall uptake (black arrow). Prominent bowel uptake of FDG was consistent with oral metformin therapy.

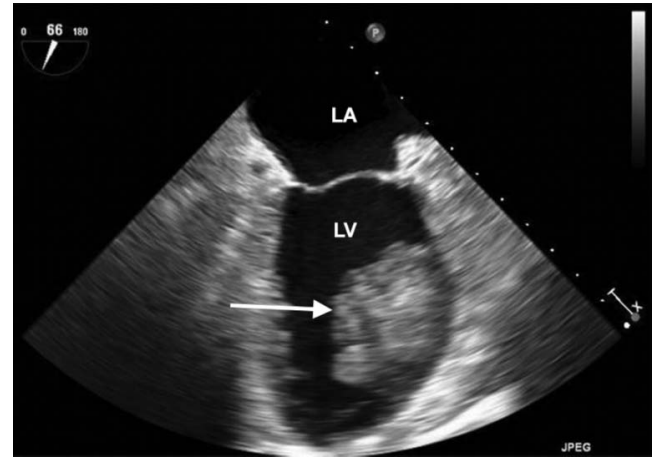

Figure 2 Transoesophageal echocardiogram. Mid-oesophageal two-chamber view. There is a large mobile mass $(4.5 \times 2.5 \mathrm{~cm})$ within the left ventricular cavity attached to the anterior wall (white arrow). It is broad-based, multilobed and has a variegated appearance. LA, left atrium; LV, left ventricle.

resection with histological examination confirming malignant melanoma (figure 5).

Cardiac metastases can occur as a complication of neoplastic disease, including lung cancer, breast cancer, lymphoma, and melanoma. While malignant melanoma frequently involves the heart, the diagnosis of cardiac involvement is often late because of the lack of specific clinical signs and reduced sensitivity of routine cardiac investigations. Consequently, ante-mortem diagnosis is uncommon even despite massive involvement. ${ }^{1}$ In recent years, however, cardiac involvement can be more accurately characterised by the use of complementing imaging modalities, including TOE, cardiac MRI and FDG PET. ${ }^{2}$ TOE is superior to transthoracic echocardiography as it can better define features such as size, mobility, and site of attachment. Cardiac MRI with gadolinium administration has been a major advance in cardiac imaging, and is particularly important to detect the extent of

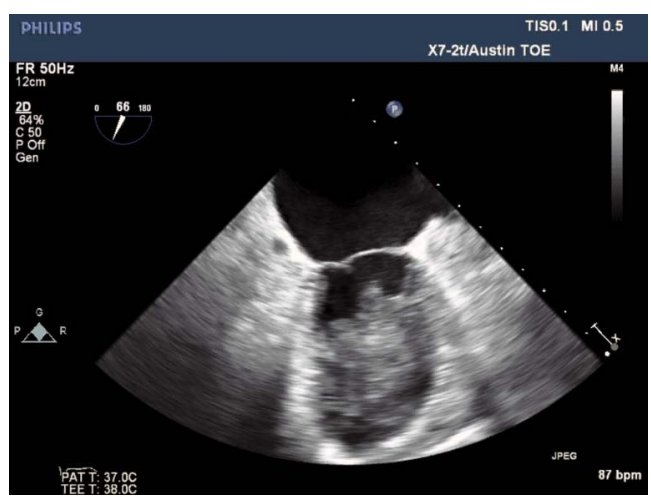

Video 1 Transoesophageal echocardiogram. Mid-oesophageal two-chamber view. Large mobile mass attached to the anterior wall of the left ventricle. 


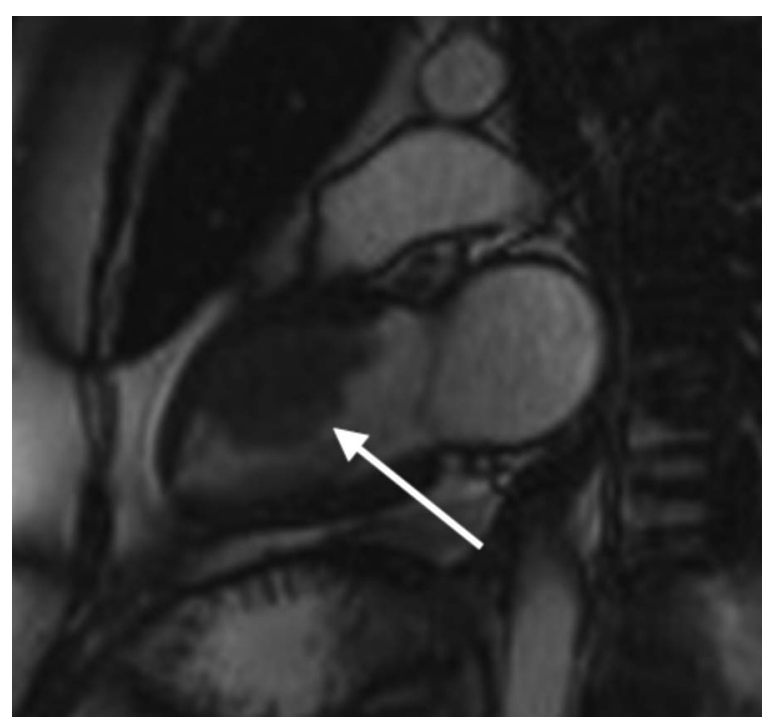

Figure 3 Cardiac MRI. Two-chamber view. A large voluminous, mobile mass is demonstrated within the left ventricular cavity (white arrow).

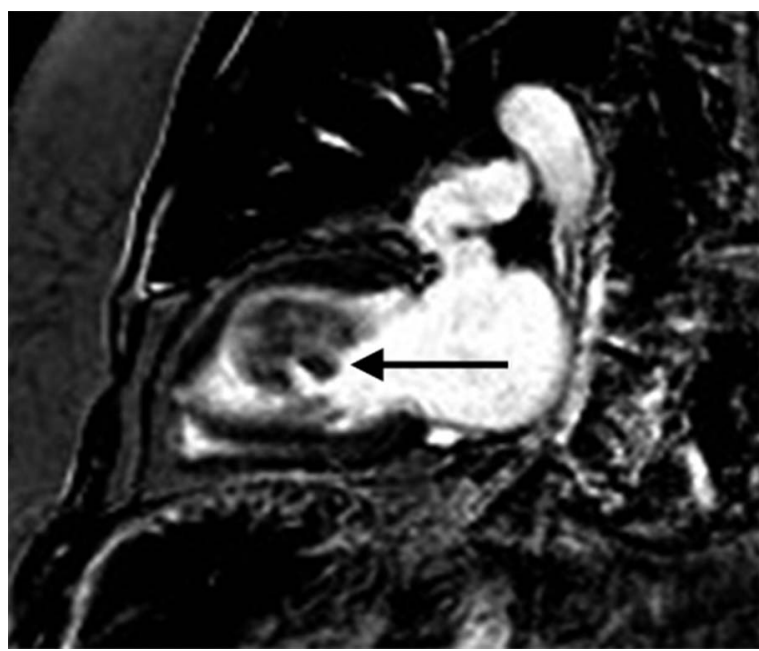

Figure 4 Cardiac MRI. Two-chamber view. Late gadolinium contrast-enhanced sequence. Left ventricular metastatic melanoma (black arrow). No evidence of macroscopic infiltration of the anterior myocardium.

myocardial tumour infiltration and to identify the small, but significant, subset of patients with isolated disease who may benefit from surgical resection. ${ }^{3}$ Efforts should be directed at early diagnosis to allow prompt treatment and avoid further disease progression or embolisation.

Despite the increasing prevalence of melanoma and its propensity to metastasise to the heart, specific recommendations to screen for cardiac involvement are currently lacking. This highlights the importance of carefully considering cardiac metastasis in patients with a history of melanoma and possible cardiac symptoms.

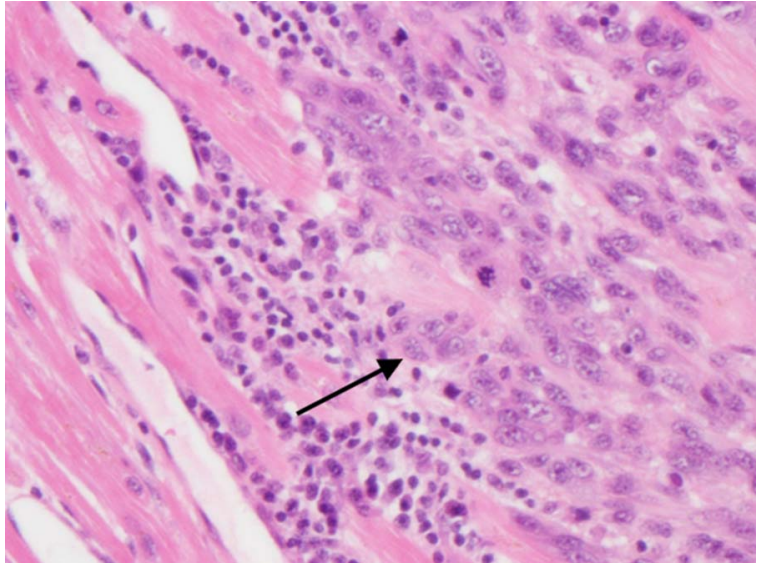

Figure 5 H\&E stained histology section of resected left ventricular mass. Section demonstrates sheets of dyscohesive, malignant epithelioid cells with prominent nucleoli and frequent mitoses (black arrow) consistent with metastatic melanoma. There was strong expression of S100 in the malignant cells.

\section{Learning points}

- Cardiac masses in patients with a known history of malignancy should raise suspicion of metastases.

- Given the propensity of melanoma to metastasise to the heart, we highlight the need of meticulous imaging in this patient cohort-even in those without specific cardiac symptoms and those seemingly at low risk for cardiac involvement.

- Early diagnosis and characterisation of cardiac involvement is important to identify the subset of patients with isolated disease who may benefit from surgical resection. However, guideline recommendations for cardiac screening are currently lacking.

Acknowledgements The authors thank Dr David Williams for kindly giving his support for their publication and providing the histopathology.

Contributors JR and SS were responsible for study concept and design. All the authors were responsible for analysis and interpretation of the data. JR, GRW and MBY contributed to drafting of the manuscript. JR, GRW and SS contributed to critical revision.

Competing interests None declared.

Patient consent Obtained.

Provenance and peer review Not commissioned; externally peer reviewed.

\section{REFERENCES}

1 Glancy DL, Roberts WC. The heart in malignant melanoma. A study of 70 autopsy cases. Am J Cardiol 1968;21:555-71.

2 Gibbs P, Cebon JS, Calafiore P, et al. Cardiac metastases from malignant melanoma. Cancer 1999;85:78-84.

3 Mousseaux E, Meunier $P$, Azancott $S$, et al. Cardiac metastatic melanoma investigated by magnetic resonance imaging. Magn Reson Imaging 1998;16:91-5. 
Copyright 2016 BMJ Publishing Group. All rights reserved. For permission to reuse any of this content visit http://group.bmj.com/group/rights-licensing/permissions.

BMJ Case Report Fellows may re-use this article for personal use and teaching without any further permission.

Become a Fellow of BMJ Case Reports today and you can:

- Submit as many cases as you like

- Enjoy fast sympathetic peer review and rapid publication of accepted articles

- Access all the published articles

- Re-use any of the published material for personal use and teaching without further permission

For information on Institutional Fellowships contact consortiasales@bmjgroup.com

Visit casereports.bmj.com for more articles like this and to become a Fellow 